\title{
DEM ACCURACY RESEARCH BASED ON UNMANNED AERIAL SURVEY DATA
}

\author{
V. M. Kurkov ${ }^{1}$, A. S. Kiseleva ${ }^{1}$ \\ ${ }^{1}$ Moscow State University of Geodesy and Cartography, Bld. 4, Gorokhovsky Ln., 105064, Moscow, Russia \\ v.kurkov@inbox.ru, ennnot@yandex.ru
}

Commission III, WG III-4b

KEY WORDS: Digital Elevation Model, UAV, SGM algorithm, Dense Matching, Dense Cloud, Multiray Photogrammetry, Expected Accuracy of Dense DEM

\begin{abstract}
:
Currently, digital elevation models (DEM) created by photogrammetric method based on unmanned aerial survey data are becoming an increasingly popular product. They are used in various areas of human activity related to modelling and analysis of terrain, namely: topography, engineering and geodetic surveys, surveying, archaeology, geomorphology, etc. The accuracy of digital surface and terrain models obtained by the photogrammetric method depends on the accuracy of aerial triangulation and dense point cloud from a number of overlapping images. In turn, the accuracy of the aerial triangulation is determined by the accuracy of the measurements of the tie points, GCP's / check points and the intersection geometry. When constructing a dense cloud using the SGM algorithm, the quality of the surface/terrain model depends not only on the accuracy of point identification, but also on filtering outliers and rejecting unreliable measurements. This article presents the results of evaluating the accuracy of creating a digital elevation model obtained by various unmanned aerial survey systems on a single test area.
\end{abstract}

\section{INTRODUCTION}

Currently, digital terrain models (DEM) created by a photogrammetric method based on data from unmanned aerial surveys are becoming more and more available. The reason for this trend is, in our opinion, based on two factors: automation of aerial survey process and photogrammetric data processing of unmanned aerial survey. The factor of greater availability of photogrammetric processing products leads to the fact that, in addition to traditional users in geodesy, cartography, cadastre, and surveying, there are users of related areas such as, but not limited to architects, archaeologists, builders, landscape design specialists and environmental monitoring. Along with improving the quality and availability of hardware and simplifying the interface of software products, we should also note the improvement in the quality and efficiency of creating output products such as dense digital terrain models and 3D textured models. Currently, the most common algorithms for constructing a dense point cloud based on a large number of overlapping images are the semiglobal identification algorithm (Hirschmuller, 2005) and its modifications (Chibunichev et al, 2015), (Gorbachev, 2014). Research and modifications of the classic SGM algorithm are aimed at obtaining subpixel identification accuracy and processing multiple source images simultaneously (Chibunichev et al, 2015), (Bethmann, Luhmann, 2015). In practice, using this method of image processing allows you to obtain digital terrain models with a resolution comparable to the GSD- pixel size on the terrain. Thus, the increased quality of aerial photography on the one hand, and the improvement of algorithms for identifying the corresponding points on the other hand, allow us to consider the photogrammetric method for obtaining dense digital terrain models as an alternative to aerial laser scanning (Haala, 2012).

\section{ACCURACY OF DENSE POINT CLOUD}

The accuracy of digital surface and terrain models obtained by the photogrammetric method depends on the accuracy of aerial triangulation and a dense point cloud from a set of overlapping images. In turn, the accuracy of the aerial triangulation is determined by the measurement accuracy of tie points, GCP's / check points and the intersection geometry on the defined point in the model.

When constructing a dense cloud using the SGM algorithm, the quality of surface/terrain model depends not only on the accuracy of point identification, but also on filtering out outliers and rejecting unreliable measurements (Haala, Rothermel, 2012).

To calculate the expected accuracy of Z-coordinate determining on a stereo pair, you can use the formula:

$$
\mathrm{m}_{z}=\mathrm{m}_{\mathrm{p}} \times \frac{f}{b}
$$

where $f=$ the focal length,

$\mathrm{b}=$ baseline at the image scale,

$\mathrm{m}_{\mathrm{p}}=$ accuracy of $\mathrm{x}$-parallax measurements in an

image.

Obviously, the lower the $\mathrm{f} / \mathrm{b}$ ratio, the higher the expected accuracy of Z-coordinate determination (height) from stereo pairs. In unmanned aerial survey to compensate for photogrammetric gaps, forward and side overlapping can reach $80 \%$, which favourably affects the identification of the corresponding points, and negatively affects the accuracy of Zcoordinates determination from adjacent images (Haala, 2011). However, the use of multiple overlapping images, including stereo pairs with favourable intersection geometry, can compensate for the negative effect of neighboring images. Experimental studies of this assumption have been carried out for various unmanned aerial survey systems at the control site. 


\section{DATA ACQUISITION}

The research was conducted at the Zaoksky testing ground of the Moscow State University of Geodesy and Cartography (MIIGAiK). This testing ground is intended for development and assessment of manned and unmanned aerial systems (Mikhajlov et al, 2011), (Kurkov et al, 2015). The testing ground is located in the Zaoksky district of the Tula region, its total area is about 200 square $\mathrm{km}$. There are various relief forms of different origins, forest areas, settlements, railways, highways, dirt roads, hydrographic objects (rivers, ponds), agricultural land and production facilities. For our experiment we choose a cross-country area of about 1 square $\mathrm{km}$ with an elevation difference of $80 \mathrm{~m}$, located on the banks of the Skniga River. Within the control area there is also a settlement with low-rise buildings.

During the experiment, an aerial survey of the study area was carried out. Geodetically, the study area includes 60 targeted GCPs determined by the GNNS observation method and 80 pickets in open areas determined using tacheometric survey. Figure 1 shows the appearance of the targeted GCP taken during satellite observation.

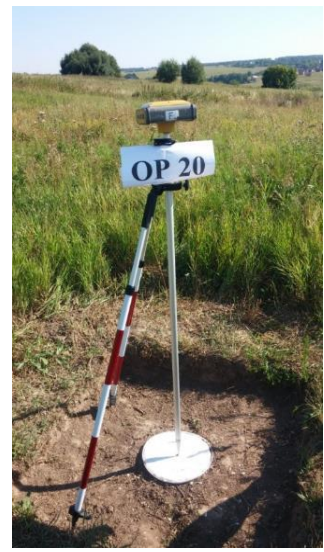

Figure 1. Appearance of the targeted GCP during observation.

A planimetric and vertical accuracy of the geodetic reference framework is $2 \mathrm{~cm}$. Figure 2 shows the location of marked control points at the study area.

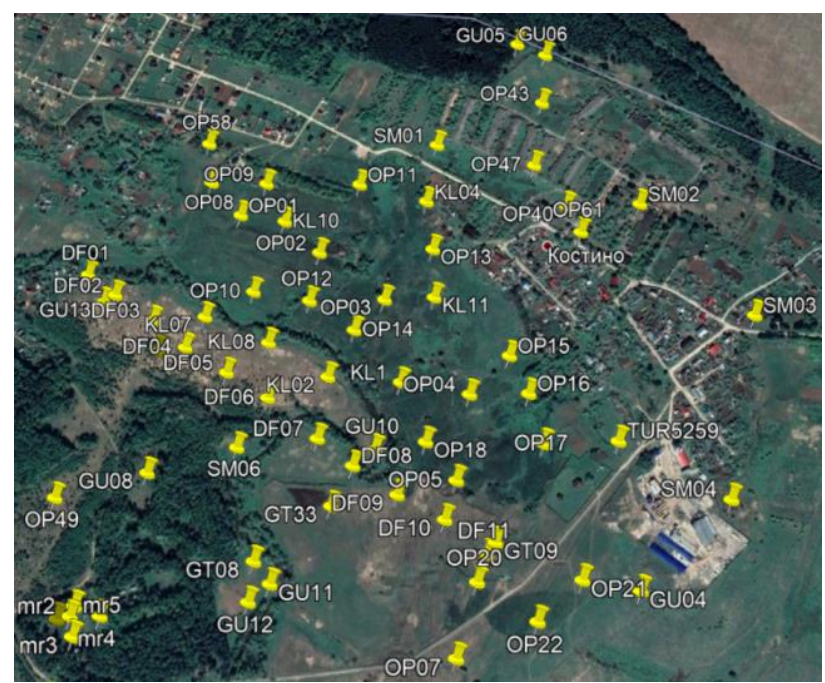

Figure 2. GCP's location at the study area
Aerial survey of the study area was performed by different unmanned aerial survey systems with different cameras and geodetic equipment on board. Fixed-wing drones, plane and quadcopters manufactured by Geoscan (www.Geoscan.aero/en/), Finco (www.unmanned.ru/en/) and DJI (www.dji.com) were used in the experiment. Figure 3 shows the UAVs used in the experiment.

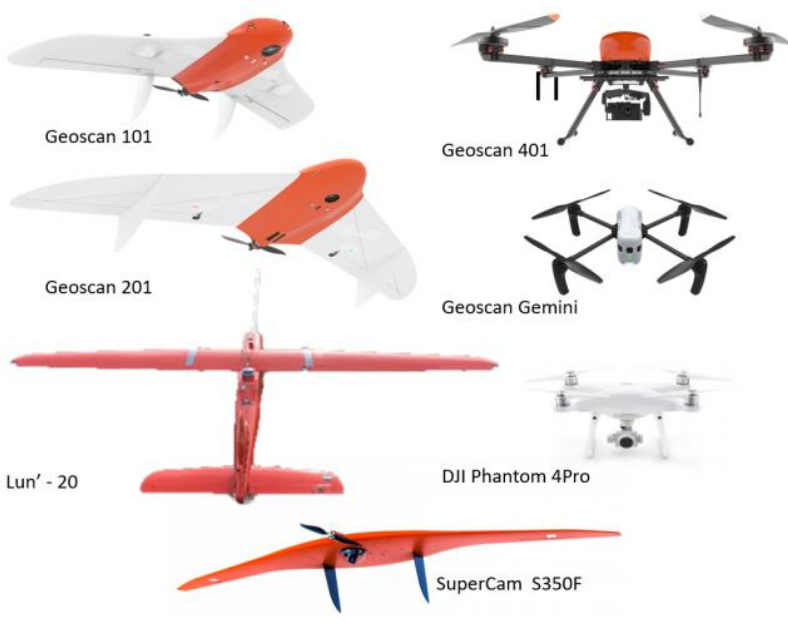

Figure 3. Appearance of UAVs used in the experiment

All boards were equipped with high-precision geodetic receivers, where the data from them after post-processing was used for aerial triangulation. Table 1 shows the technical characteristics of the aerial survey systems used in this experiment.

\begin{tabular}{|l|l|l|l|}
\hline UAV/ H, m & $\begin{array}{l}\text { UAV } \\
\text { type }\end{array}$ & Gimbal & GNNS receiver \\
\hline Geoscan 101 & wing & none & OEM Topcon B 111 \\
\hline Geoscan 201 & wing & none & OEM Topcon B 111 \\
\hline Geoscan 401 & copter & 2-axis & OEM Topcon B 111 \\
\hline $\begin{array}{l}\text { Geoscan } \\
\text { Gemini }\end{array}$ & copter & none & OEM Topcon B 111 \\
\hline $\begin{array}{l}\text { SuperCam } \\
\text { S350F }\end{array}$ & wing & none & Javad TRE-3N \\
\hline DJI P4RTK & copter & 3-axis & $\begin{array}{l}\text { Unicorecomm } \\
\text { UM482 }\end{array}$ \\
\hline Lun'-20 & plane & none & Javad TRE-3N \\
\hline
\end{tabular}

Table 1. UAV technical specifications

In this experiment, the drones were equipped with cameras that differ in purpose, type of shutter, frame size and sensor parameters. Figure 4 shows the appearance of cameras used in the experiment.

In addition to a specialized aerial survey camera (PhaseOne IXU-RS1000), compact full-frame Sony cameras (Sony DSC RX-1 and Sony DSC-RX1RM2) were refined by drone manufacturers during the integration on board the UAV and then used for aerial survey. The Sony UMC-R10C Mapping System is positioned by the manufacturer as a compact aerial survey system for small aircraft with an interface ready to be integrated on board without any additional modifications. The DJI Phantom 4 RTK is positioned as an aerial survey system with the FC6310R camera equipped with a central shutter. 


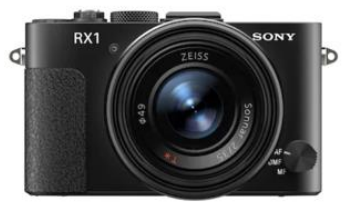

Sony DSC RX1

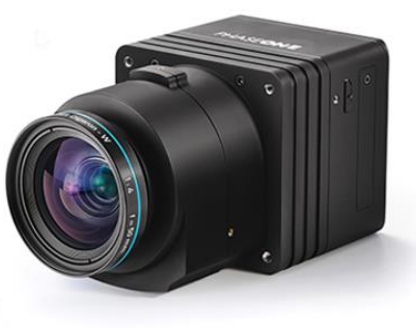

PhasOne IXU-RS1000

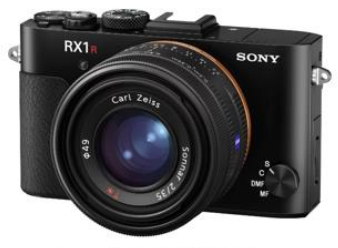

Sony DSC RX1RM2

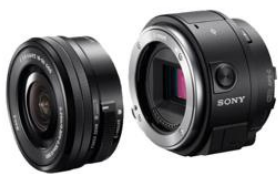

Sony UMC RX10C

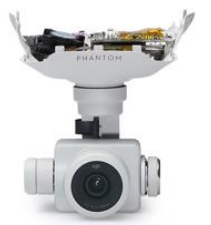

DJI FC6310R
Figure 4. Appearance of the cameras used in the experiment

Detailed information about the used cameras is presented in Table 2. Table 3 shows aerial survey parameters that were used during the planning of the flight mission.

\begin{tabular}{|l|l|l|l|}
\hline \multirow{2}{*}{ UAV } & \multicolumn{3}{|c|}{ Camera } \\
\cline { 2 - 4 } & \multicolumn{1}{|c|}{ Name } & $\begin{array}{l}\text { Matrix /pixel } \\
\text { size, } \mu \mathrm{m}\end{array}$ & Image size \\
\hline $\begin{array}{l}\text { Geoscan } \\
\text { 101, 201, } \\
401\end{array}$ & $\begin{array}{l}\text { Sony DSC } \\
\text { RX-1 FF, 20 Mp/ 6 }\end{array}$ & $\begin{array}{l}6000 \times \\
4000\end{array}$ \\
\hline $\begin{array}{l}\text { Geoscan } \\
\text { Gemini }\end{array}$ & $\begin{array}{l}\text { Sony UMC- } \\
\text { R10C } \\
\text { Mapping } \\
\text { System }\end{array}$ & & \\
\hline $\begin{array}{l}\text { SuperCam } \\
\text { S350F }\end{array}$ & $\begin{array}{l}\text { Sony DSC- } \\
\text { RX1RM2 }\end{array}$ & $\begin{array}{l}\text { FF, 42 Mp/ } \\
4.5\end{array}$ & $\begin{array}{l}5456 \times \\
3632\end{array}$ \\
\hline $\begin{array}{l}\text { DJI } \\
\text { P4RTK }\end{array}$ & FC6310R & $20 \mathrm{Mp} / 2.4$ & $5472 \times 3648$ \\
\hline Lun'-20 & PhaseOne & $101 \mathrm{Mp} / 4.6$ & $\begin{array}{l}11608 \times \\
8708\end{array}$ \\
\hline
\end{tabular}

Table 2. Camera technical specifications

\subsection{Geodetic Data Processing}

All drones in this experiment were equipped with precise geodetic receivers on board. For all boards except the DJI Phantom 4 RTK, the surveying was performed as follows: two base stations were used during the flights, one of which was located directly near the take-off point. Observations on both receivers were made in "static" mode with a frequency of 10 Hz. On-board receivers recorded measurements in "kinematic" mode, also with a frequency of $10 \mathrm{~Hz}$. Post-processing of flight trajectory was performed in Javad Justin or Topcon Magnet Tool software using the PPK (Post Processing Kinematic) method. Trajectory adjustment was performed using two base stations simultaneously. Then, using the data on the shutter time (Event Markers), the precise coordinates of the projection centres were calculated. DJI Phantom 4 RTK does not require post-processing of on-board data, as the receiver operates in RTK (Real Time Kinematic) mode and receives real-time corrections from the DJI D-RTK 2 ground base station. The precise coordinates of the projection centres are recorded in the EXIF data of the images on board.

\subsection{Photogrammetric Processing}

The data obtained were processed in the following process chain:

- $\quad$ aerial triangulation;

- $\quad$ creation of a dense point cloud;

- $\quad$ DEM creation;

- $\quad$ DEM quality assessment by targeted control points, by pickets.

Photogrammetric processing of the received data was performed on digital photogrammetric systems Agisoft Metashape (Geoscan - 101, 201, 401, Gemini) PHOTOMOD UAS (SuperCam S250F, Lun'-20) and Pix4D Mapper (DJI Phantom 4 RTK).

\begin{tabular}{|l|l|l|}
\hline UAV/ H, m & GSD, $\mathrm{cm}$ & $\mathrm{PX}_{\mathrm{P}} / \mathrm{P}_{\mathrm{Y}} \%$ \\
\hline Geoscan 101/200 & 4 & $70 / 60$ \\
\hline Geoscan 101/400 & 8 & $70 / 60$ \\
\hline Geoscan 201/200 & 4 & $70 / 60$ \\
\hline Geoscan 201/400 & 8 & $70 / 60$ \\
\hline Geoscan 401/200 & 4 & $70 / 60$ \\
\hline Geoscan 401/200 & 8 & $70 / 60$ \\
\hline Geoscan Gemini/190 & 4 & $80 / 60$ \\
\hline Geoscan Gemini/250 & 8 & $80 / 60$ \\
\hline SuperCam S350F/250 & 3 & $80 / 60$ \\
\hline DJI P4RTK/100 & 3 & $80 / 60$ \\
\hline Lun'-20/380 & 3.5 & $70 / 60$ \\
\hline Lun'-20/380 & 9 & $70 / 60$ \\
\hline
\end{tabular}

Table 3. Aerial survey parameters used in the experiment

From the data of each flight, projects were created where the projection centres and the targeted GCPs were uploaded. The exception was the data from DJI Phantom 4 RTK because external orientation parameters were loaded automatically from EXIF-data after adding pictures to the project. Then, in all softwares, automatic measurement of tie points was launched with further adjustment of the aerial triangulation network. Bundle adjustment with self-calibration was performed for each project. An exception was the project based on the data captured by the PhaseOne IXU-RS1000 camera, as this camera was pre-calibrated on a test object. The corresponding file with internal orientation parameters was created in PHOTOMOD software, then assigned to the images, and self-calibration was disabled during the adjustment. Precise coordinates of projection centres were used for georeferencing, and targeted GCPs were used as check points.

\subsection{The Results of Aerial Triangulation}

Table 4 shows the RMS of the projection centres after adjustment. 


\begin{tabular}{|l|c|c|c|}
\hline \multirow{2}{*}{ UAV/ H, m } & \multicolumn{3}{|c|}{ Projection Centres } \\
\cline { 2 - 4 } & $\begin{array}{l}\text { RMSx, } \\
\mathrm{cm}\end{array}$ & $\begin{array}{l}\text { RMSy, } \\
\mathrm{cm}\end{array}$ & $\begin{array}{l}\text { RMSz, } \\
\mathrm{cm}\end{array}$ \\
\hline Geoscan 101/200 & 4.2 & 4.0 & 3.7 \\
\hline Geoscan 101/400 & 10.8 & 9.7 & 4.1 \\
\hline Geoscan 201/200 & 2.4 & 2.5 & 1.8 \\
\hline Geoscan 201/400 & 3.0 & 2.7 & 3.7 \\
\hline Geoscan 401/200 & 4.5 & 3.5 & 6.9 \\
\hline Geoscan 401/400 & 6.8 & 4.9 & 11.6 \\
\hline Geoscan Gemini/190 & 3.4 & 3.0 & 5.0 \\
\hline Geoscan Gemini/250 & 5.0 & 5.3 & 4.5 \\
\hline SuperCam S350F/250 & 2.6 & 2.7 & 2.4 \\
\hline DJI P4 RTK/100 & 4.0 & 4.0 & 6.0 \\
\hline Lun'-20/380 & 4.4 & 8.2 & 5.9 \\
\hline Lun'-20/980 & 5.2 & 6.7 & 3.8 \\
\hline
\end{tabular}

Table 4. The RMS of projection centers after adjustment

Figure 5 shows the RMS diagram of the projection centers.

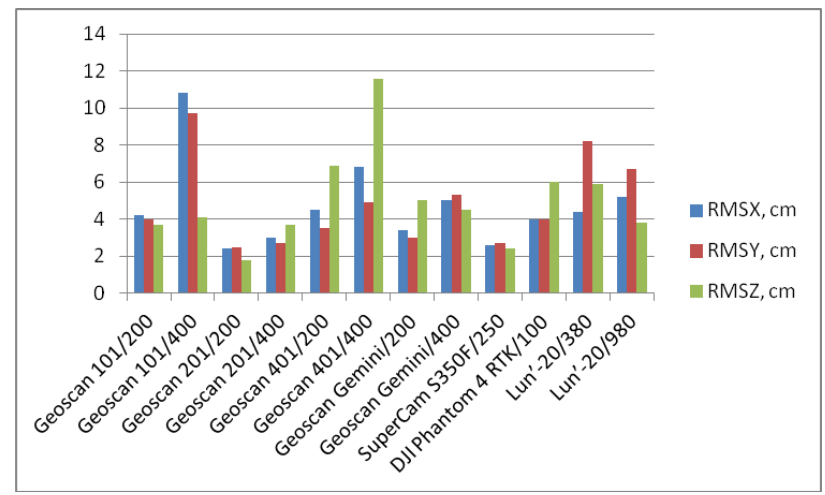

Figure 5. The RMS diagram of the projection centers

As can be seen from the error diagram, the spread in the standard deviations is insignificant, and is in the centimeter range, which confirms the theoretical expectations. The root mean square errors at the control points, for which targeted GCPs were used, are presented in table 5.

\begin{tabular}{|l|c|c|c|}
\hline UAV/ H, m & $\begin{array}{l}\text { GSD, } \\
\mathrm{cm}\end{array}$ & $\begin{array}{l}\mathrm{RMS}_{\mathrm{XY}}, \\
\mathrm{cm}\end{array}$ & $\begin{array}{l}\mathrm{RMS}_{\mathrm{Z}}, \\
\mathrm{cm}\end{array}$ \\
\hline Geoscan 101/200 & 3.8 & 7.0 & 7.5 \\
\hline Geoscan 101/400 & 7.8 & 8.3 & 9.6 \\
\hline Geoscan 201/200 & 4.0 & 5.5 & 5.0 \\
\hline Geoscan 201/400 & 7.9 & 7.1 & 8.8 \\
\hline Geoscan 401/200 & 3.8 & 5.5 & 8.8 \\
\hline Geoscan 401/400 & 8.1 & 6.1 & 9.6 \\
\hline Geoscan Gemini/190 & 3.7 & 5.5 & 5.8 \\
\hline Geoscan Gemini/250 & 7.8 & 7.9 & 11.7 \\
\hline SuperCam S350F/250 & 3.2 & 4.7 & 5.4 \\
\hline DJI P4 RTK/100 & 3.4 & 5.0 & 6.5 \\
\hline Lun'-20/380 & 3.5 & 3.0 & 3.0 \\
\hline Lun'-20/980 & 9.0 & 4.2 & 5.0 \\
\hline
\end{tabular}

Table 5. The RMS at the control points

Figure 6 shows a diagram of the root mean square errors at the control points. The results of the accuracy assessment after adjustment characterize the real accuracy of photogrammetric

measurements, which should be expected as a result of photogrammetric processing.

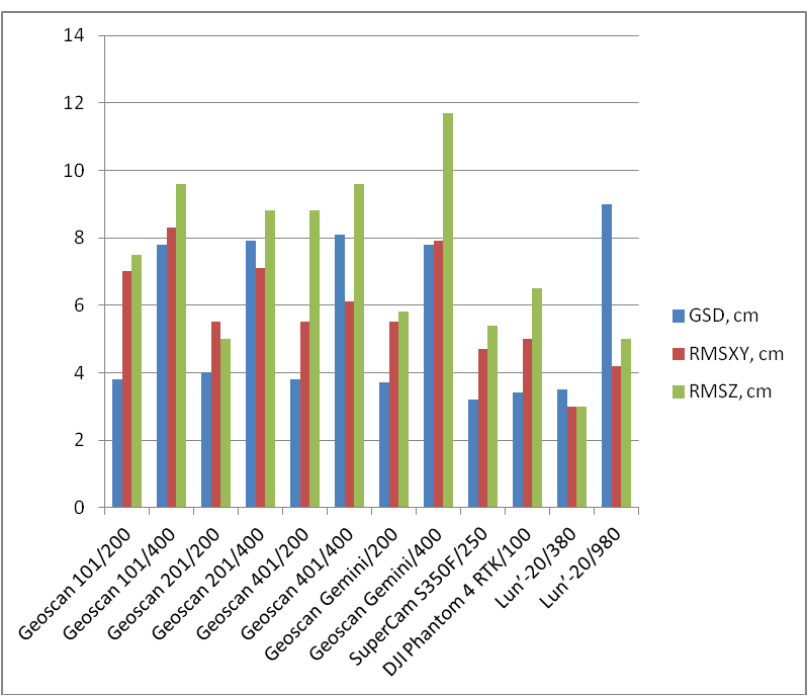

Figure 6. The RMS diagram of the control points after adjustment

\subsection{DEM creation and Quality Control}

After aerial triangulation from the data of each flight, dense elevation models were created in the same software products where the adjustment was performed. Then, the accuracy of the obtained DEMs was estimated with targeted control points and pickets. Figure 7 shows the targeted control points and pickets, which were used to assess the accuracy of the DEM.

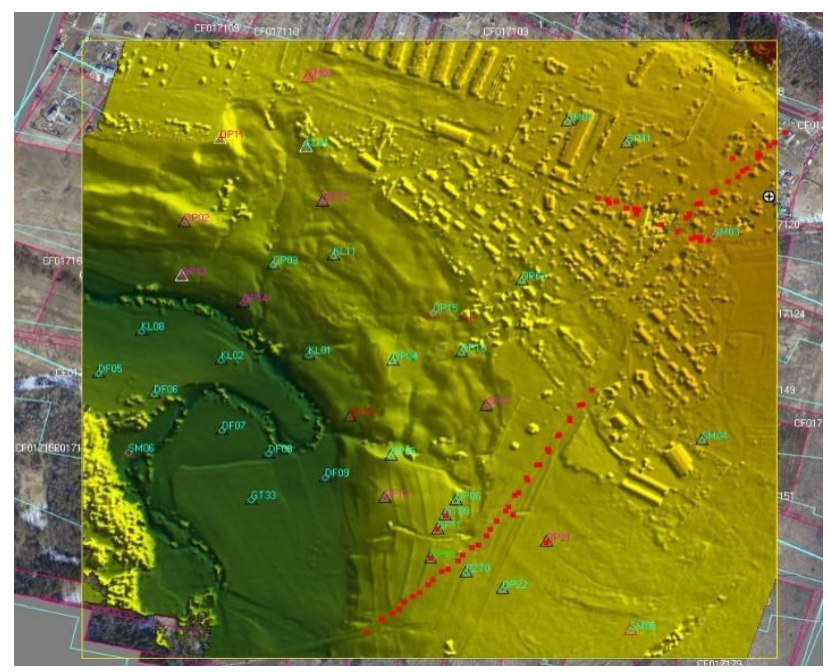

Figure 7. Location of the targeted check points and pickets

The results of the accuracy assessment of the obtained DEMs are shown in Table 6.

\section{CONCLUSIONS}

In this article, we tried to summarize the results of experimental studies on the accuracy of photogrammetric data processing of various unmanned aerial survey systems. Taking into account the dependence of the absolute accuracy of 
coordinate determination on the spatial resolution on the ground, we will give the accuracy of aerial triangulation and DEM in relation to the spatial resolution.

\begin{tabular}{|l|c|c|c|}
\hline UAV/ H, m & $\begin{array}{c}\text { GSD, } \\
\text { cm }\end{array}$ & $\begin{array}{l}\text { RMS in } \\
\text { height, cm }\end{array}$ & $\begin{array}{l}\text { RMS/ } \\
\text { GSD ratio }\end{array}$ \\
\hline Geoscan 101/200 & 3.8 & 7.0 & 1.8 \\
\hline Geoscan 101/400 & 7.8 & 20.2 & 2.6 \\
\hline Geoscan 201/200 & 4.0 & 9.8 & 2.4 \\
\hline Geoscan 201/400 & 7.9 & 19.1 & 2.4 \\
\hline Geoscan 401/200 & 3.8 & 9.8 & 2.6 \\
\hline Geoscan 401/400 & 8.1 & 16.5 & 2.0 \\
\hline Geoscan Gemini/190 & 3,7 & 11.5 & 3.1 \\
\hline Geoscan Gemini/250 & 7,8 & 14.1 & 1.8 \\
\hline SuperCam S350F/250 & 3,2 & 9.5 & 2.9 \\
\hline DJI P4RTK/100 & 3.4 & 9.9 & 2.9 \\
\hline Lun'-20/380 & 3.5 & 8.0 & 2.3 \\
\hline Lun'-20/980 & 9 & 14.1 & 1.6 \\
\hline
\end{tabular}

Table 6. DEM accuracy assessment by check points and pickets

The use of a common control area with a large number of targeted GCPs allows to substantiate the statistical reliability of the obtained estimates in all implemented projects. If the spatial resolution is taken as one, the following conclusion can be drawn for all experiments:

- the accuracy of photogrammetric measurements (aerial triangulation adjustment) was $0.5-1.8$ pixels in plan and $0.8-2.3$ pixels in height;

- $\quad$ DEM accuracy varies between $1.6-3.1$ pixels.

A summary of the results relative to the GSD is given in Table 7 , and Figure 8 shows a diagram of the results.

\begin{tabular}{|l|l|l|l|l|}
\hline UAV/ H, m & GSD, & \multicolumn{2}{|l|}{ Adjustment RMS } & DEM \\
\cline { 3 - 4 } & $\mathrm{km}$ & $\begin{array}{l}\text { RMSXY/ } \\
\text { GSD }\end{array}$ & $\begin{array}{l}\text { RMSz } \\
\text { /GSD }\end{array}$ & $\begin{array}{l}\text { RMSD } \\
\text { GSD }\end{array}$ \\
\hline Geoscan 101/200 & 3.8 & 1.8 & 1.1 & 1.8 \\
\hline Geoscan 101/400 & 7.8 & 1.1 & 1.2 & 2.6 \\
\hline Geoscan 201/200 & 4.0 & 1.4 & 1.2 & 2.4 \\
\hline Geoscan 201/400 & 7.9 & 0.9 & 1.1 & 2.4 \\
\hline Geoscan 401/200 & 3.8 & 1.5 & 2.3 & 2.6 \\
\hline Geoscan 401/400 & 8.1 & 0.8 & 1.2 & 2.0 \\
\hline Geoscan Gemini/190 & 3.7 & 1.5 & 1.6 & 3.1 \\
\hline Geoscan Gemini/250 & 7.8 & 1.0 & 1.5 & 1.8 \\
\hline SuperCam S350F/250 & 3.2 & 1.5 & 1.7 & 2.9 \\
\hline DJI P4RTK/100 & 3.4 & 1.5 & 1.9 & 2.9 \\
\hline Lun'-20/380 & 3.5 & 0.8 & 0.8 & 2.3 \\
\hline Lun'-20/980 & 9.0 & 0.5 & 1.2 & 1.6 \\
\hline
\end{tabular}

Table 7. Estimation of accuracy relative to GSD

In this experiment, both copter- and aircraft-type UAV were used. All of them are equipped with precise geodetic receivers that provide precise projection centres either in post-processing or real-time mode. Various cameras were used, both specialized and adapted by the UAV manufacturers for aerial survey. Photogrammetric processing was carried out on various photogrammetric systems, using strict methods, both with selfcalibration and pre-defined camera parameters.

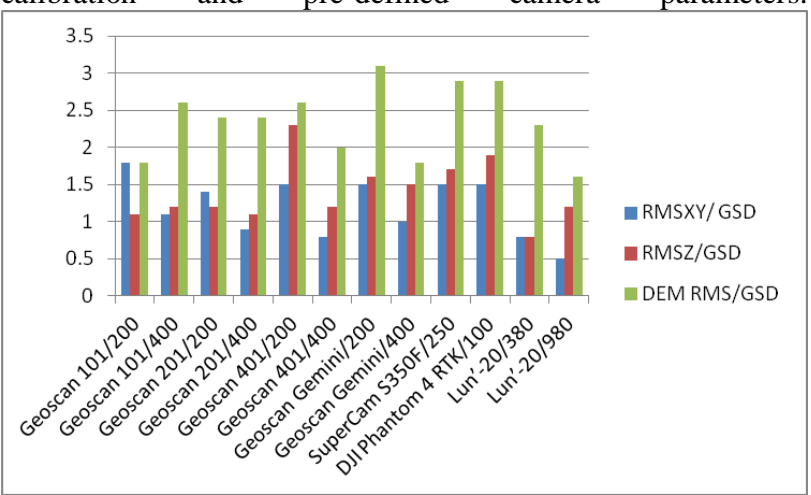

Figure 8.Diagram of the accuracy estimation diagram relative to GSD

Despite the variety in UAVs, cameras, and software products used in the course of the experiment, the results of DEM accuracy assessment were obtained that correspond to the theoretical expectations, and show the practical range of UAV application in topography, surveying, engineering and other areas where DEMs are in demand.

\section{ACKNOWLEDGEMENTS}

The work was performed with the support by Grant 17-2904410 of Russian Foundation for Basic Research (RFBR).

\section{REFERENCES}

Bethmann F., Luhmann T., 2015: Semi-Global Matching in Object Space. ISPRS Volume XL-3/W2, pp. 23-30.

Chibunichev A., Mikhailov A, Starshov V, 2015: Automatic Dense Point Generation from a set of images based on SGM algorithm. Geodesy and Aerophotosurveying, N 2, pp. 14-18.

Gorbachev V.A., 2014: Dense Reconstruction of Area Relief Based on Modified Semi Global Matching Algorithm. Izvestia RAN. Teoriya i systemy upravleniya, 2014, N 2 pp. 66-77

Haala,N., 2011: Multiray Photogrammetry and Dense Image Matching. Photogrammetric Week, pp. 185-195.

Haala. N., Rothermel. M., 2012: Dense Multi-Stereo Matching for High Quality Digital Elevation Models. PFG Photogrammetrie, pp. 331-343.

Hirschmuller H., 2005: Accurate and efficient stereo processing by semi-global matching and mutual information // IEEE Conf. on Computer Vision and Pattern Recognition. San Diego, California, USA, V. 2. P. 807-814.

Kurkov V.M., Chibunichev A.G., and A.V. Grechishev, 2015: Testing of Aerial Survey Systems at the MIIGAiK Testing Ground for Implementing of Innovation Technologies in the Geodesic and Mapping Production. Geoinformation Technologies and Space Monitoring, Vol. 3, pp. 71-81. 
Mikhailov A.P., Kurkov V.M., Chibunichev A.G., 2011: Testing area geopolygon MIIGAiK for research, calibration and certification of unmanned aerial systems. From Imagery to Map: Digital Photogrammetric Technologies: Materials of the 11th International Scientific and Technical Conference, Barcelona, Spain, pp. 28-29. 